\title{
Automating Shallow Seismic Imaging
}

\author{
Final Technical Report \\ Grant period: September 15, 1997-September 14, 2004
}

Date Published: December 2004

Don W. Steeples

\section{PREPARED FOR THE UNITED STATES DEPARTMENT OF ENERGY/ENVIRONMENTAL MANAGEMENT SCIENCE PROGRAM}

Work performed under Award No. DE-FG07-97ER14826.

Any opinions, findings, and conclusions or recommendations expressed in this material are those of the author and do not necessarily reflect the views of the Department of Energy. 
Award Number: Project Title: Covering Period: Date of Report:

Awardee:

Project Director:

Project Team:
DE-FG07-97ER14826 ; EMSP 73731 ; FED 13880-DOE

Automating Shallow Seismic Imaging

September 15, 1997 through September 14, 2004

December 2004

The University of Kansas Center for Research, Inc. (KUCR)

Youngberg Hall, 2385 Irving Hill Road

The University of Kansas - West Campus

Lawrence, KS 66045-7563

Don W. Steeples (PI), 785-864-2730, don@ku.edu

Roland Hirsch, SC-73

U.S. Dept. of Energy

19901 Germantown Rd, Rm J-125

Germantown, Maryland 80874

(301) 903-9009

roland.hirsch@science.doe.gov

Beth Moore

U.S. Dept. of Energy

1000 Independence Avenue

Washington, D.C. 20585

(202) 586-6334

beth.moore@em.doe.gov

Maria DeMott

U.S. Dept of Energy/ Idaho Operations Office

208-526-8600 mitchemm@id.doe.gov

Barbara J. Armbrister

KUCR Business Officer, The University of Kansas

785-864-3441 barmbrister@ku.edu;

Acknowledgment: This material is based upon work supported by the U.S. Department of Energy under Award No. DE-FG07-97ER14826.

Disclaimer: Any opinions, findings, and conclusions or recommendations expressed in this material are those of the author and do not necessarily reflect the views of the Department of Energy.

\section{EXECUTIVE SUMMARY:}

This is a final report on seven years of shallow-seismic reflection research directed at improving geophysical imaging of possible contaminant flow paths. Thousands of chemically contaminated sites exist in the United States, including at least 3,700 at Department of Energy (DOE) facilities. Imaging technologies such as shallow seismic reflection (SSR) and ground-penetrating radar (GPR) sometimes are capable of identifying geologic conditions that might indicate preferential contaminant-flow paths. Historically, SSR has been used very little at depths shallower than $30 \mathrm{~m}$, and even more rarely at depths of $10 \mathrm{~m}$ or less. Conversely, GPR is rarely useful at depths greater than $10 \mathrm{~m}$, especially in areas where clay or other electrically conductive materials are present near the surface.

The primary focus of the first three years of research was to image the cone of depression around a pumping well using seismic methods, supplemented by GPR methods. We collected data from a well site at which drawdown equilibrium had been reached and at another well site during a pumping test. Data analysis disclosed that although we were successful in imaging the water table using SSR (Johnson 2003), we were not able to explicitly delineate the cone of depression. Consequently, the effort to image the cone of depression was only partially successful (Johnson 2003; Baker et al. 2000b), but peripheral results included development of SSR methods for depths shallower than one meter, a depth range that had not been achieved before (Baker 1999; Baker et 
al. 1999a). Imaging at such shallow depths, however, requires geophone intervals of the order of $10 \mathrm{~cm}$ or less, which makes such surveys very expensive in terms of human time and effort. We also showed that SSR and GPR could be used in a complementary fashion to image the same volume of earth at very shallow depths (Baker et al. 2001).

The primary research focus of the second three-year period of funding was to develop and demonstrate an automated method of conducting two-dimensional (2D) shallow-seismic surveys with the goal of saving time, effort, and money. Tests involving the second generation of the hydraulic geophone-planting device dubbed the "Autojuggie" showed that large numbers of geophones can be placed quickly and automatically and can acquire high-quality data, although not under rough topographic conditions. In some easy-access environments, this device could make SSR surveying considerably more efficient and less expensive, particularly when geophone intervals of $25 \mathrm{~cm}$ or less are required.

The most recent research analyzed the difference in seismic response of the geophones with variable geophone spike length and geophones attached to various steel media. Experiments investigated the azimuthal dependence of the quality of data relative to the orientation of the rigidly attached geophones. Other experiments designed to test the hypothesis that the data are amplified in much the same way that an organ pipe amplifies sound have so far proved inconclusive.

Taken together, the positive results show that SSR imaging within a few meters of the earth's surface is possible if the geology is suitable, that SSR imaging can complement GPR imaging, and that SSR imaging could be made significantly more cost effective, at least in areas where the topography and the geology are favorable. On the negative side, we were not wholly successful in our effort to image a cone of depression around a pumping well. This was caused in part by clay lenses that partially perched the water table at two of the sites tested, and by lack of sufficient drawdown at a third site (Johnson 2003).

\section{RESULTS IN COMPARISON TO OBJECTIVES}

The most notable research results stemming from the first three years of our EMSP funding (1997-2000) are summarized in several refereed scientific papers documenting the procedures used to achieve seismic imaging at ultrashallow (<3 m) depths [see Refereed Papers 1997-2004 below]. Progress in this area was attributable largely to an improved ability to measure the nearsource wavefield. To accomplish this, we collected data using very small energy sources and single, $100-\mathrm{Hz}$ geophone-group intervals of $5 \mathrm{~cm}$. In contrast, typical "shallow" seismic surveys often use geophone-group intervals of $1 \mathrm{~m}$ or more. Because we increased the spatial density of the geophones by a factor of at least 20 , we were able to delineate and improve the coherence of the ultrashallow reflections relative to other interfering phases. Increasing the spatial density of the geophones, however, comes at a price in time and effort. It is this aspect of the work that we attempted to alleviate during the second three-year period of funding by concentrating on the development of the automated geophone-planting device (the Autojuggie).

Another of the objectives of the first three years of EMSP funding was to image a cone of depression around a pumping well using both seismic data and GPR. Although we were successful in imaging the same geologic interfaces with both $P$-wave SSR and GPR methods (Baker et al. 1999b, 2001) as well as imaging the water table, we have not been able explicitly to delineate the cone of depression around a pumping well (Johnson 2003). We believe this is due partly to the depositional complexity of the alluvial aquifers at the test sites and partly to the gradational nature of the capillary fringe found immediately above the water table. Based on these experiments, we have 
concluded that to obtain a useful geophysical image (1) the aquifer in which the pumping occurs must be in direct communication with the water table, (2) the aquifer must be either unconfined or semi-confined, and (3) sediment must have sufficient permeability to be capable of fully dewatering during pumping.

In the second period of funding (2000-2004), we built and field-tested first- and secondgeneration versions of the Autojuggie and attempted to monitor the cone of depression of pumping wells at two sites. Research results from the entire funding period have been reported in seven University of Kansas master's theses (Pavlovic 2000; Spikes 2002; Blair 2003; Johnson 2003; Clark 2004; Sloan 2005; Vincent 2005) and three Ph.D. dissertations (Schmeissner 1998; Baker 1999; Ralston 2003) and published in refereed scientific journals and conference proceedings [see complete lists below].

We have confirmed that a task-specific mechanical device can be used to emplace large numbers of vertical geophones both quickly and effectively. We also discovered that threecomponent (3C) geophones can be planted in a similar way. However, wave modes in the rigid medium used to connect the geophones complicated the analysis of shear- and Love waves in data acquired with $3 \mathrm{C}$ geophones planted automatically. Despite these difficulties, we made progress in understanding and implementing ultrashallow, 3C seismic methods (Ralston et al. 2002; Ralston 2003).

In addition to demonstrating the feasibility of the Autojuggie concept as outlined above, we considered the following variables:

(1) cross-sectional shape of the rigid medium to which the geophones are attached,

(2) rigid medium material; PVC vs. steel,

(3) optimum spike-length of auto-planted geophones,

(4) the amount of downward force to be applied and maintained on the rigid medium both during geophone planting and as data are acquired, and

(5) whether, for each shot, the structural frame of the Autojuggie (and thus its added mass) should be detached temporarily from the rigid medium used to hold the geophones during data acquisition.

Blair (2003) demonstrated that we improve data collection by mounting geophones on lengths of $12.5-\mathrm{cm}$-square steel tubing rather than on channel iron. We reproduced these results at the same site on different days and at different sites. The results of experiments incorporating different shapes of steel geophone-holding media are one of the surprises to emerge from our EMSP research. We do not yet understand why square tubing appears to be superior to channel iron or to the other media shapes with which we have experimented. Furthermore, the square tubing seems to yield seismic data superior to data collected with geophones planted by conventional means.

Clark (2004) undertook experiments to test our working hypothesis that we may be encountering a phenomenon in which the data are being amplified in much the same way that an organ pipe amplifies sound. We tested varying length and varying diameter round pipes and square tubing (with closed as well as open ends); the results were not conclusive. In addition to potential benefits with respect to seismic data collection, round pipes and square tubing offer the advantage of enclosure, i.e., they provide increased robustness in the field because both the geophones and their cables are protected from weather, entanglement, and damage. Clark (2004) also tested PVC vs. steel pipe rigidly attached geophones and concluded that steel is preferable for the automatic planting of geophones. 
Additional investigations were undertaken to test the other variables listed above. Blair (2003) conducted experiments with variable geophone spike lengths, using spikes up to $27 \mathrm{~cm}$ long. These tests were conducted at one site to determine the effects of geophone spike length on time- and frequency-domain seismic data recorded by geophones rigidly attached to channel iron and planted automatically using the hydraulic device (Blair et al. 2003a\&b). At the selected test site, spike length did not appear to be a significant factor in terms of data quality.

Blair's work with hollow-steel tubing (2003a) showed a significant reduction in airwave coherency compared to a control line of traditionally hand-planted geophones when used in 2-D walkaway surveys. Vincent et al. (2004b) showed that the reduction in airwave coherency is dependent on the azimuth of the source location in relation to the steel-tubing receiver array. Data recorded from shot locations along a line orthogonal to the steel-tubing orientation exhibited a larger amplitude airwave that remained coherent in the data for a longer period of time than when a traditional array of hand-planted geophones was used to record data. These findings may impact geophone array orientation for shallow 3-D seismic surveys using rigidly interconnected geophones.

Spikes et al. (2001a) showed that effective geophone mass (i.e., downward force) does not have a significant effect on data quality. The present Autojuggie weighs about $3200 \mathrm{lbs}$., which provides a downward pressure of only about $44 \mathrm{lbs}$. for each of the 72 geophones. Given the present configuration of the Autojuggie, the available downward force is not sufficient to push the geophones firmly into extremely hard ground. Constructing a heavier next-generation Autojuggie would solve this difficulty and is being studied.

Finally, the structural frame of the Autojuggie presents a dilemma. After the test-line geophones are pressed into the ground by the hydraulic mechanism, we have found it necessary to detach the frame of the Autojuggie from the steel medium to which the geophones are fastened. However, by removing a single steel, connecting pin from the clevis of each hydraulic cylinder, we have been able to detach the frame quickly and easily from the rigid connecting medium. When we are ready to move the geophones to their next position, we then reconnect the hydraulic cylinders to the rigid medium by reinserting the pins. Alternatively, the development of digital filtering could solve the noise problem induced in the geophones by the vibration of the frame of the Autojuggie (Ralston 2003), which would allow fieldwork to progress even faster.

In addition to SSR applications, we have found that the Autojuggie is capable of collecting data for use in surface-wave studies (Tian et al. 2003a; Tian et al. 2003b) and in seismic refraction work. Conceivably, work by Tian et al. (2003a\&b) could be developed further to perform, for example, seismic surface-wave studies using robotic methods in areas where human safety is a major issue. This might include DOE sites at which human occupancy is not feasible because of radiation or other hazardous-materials issues. With further research into the difficulties identified by Ralston (2003), the Autojuggie also could be used for $3 \mathrm{C}$ seismic surveys in both two and three dimensions.

\section{PROJECT SUMMARY, 1997-2004}

The original hypothesis was that improved shallow, high-resolution seismic reflection techniques could be developed that, in concert with GPR, would assist in characterizing hydrologic-transport parameters at environmentally sensitive sites at a level not possible before. Both techniques are non-invasive and can be used in situ; combined they offer the prospect of improved near-surface imaging with minimal environmental impact. 
Establishing the spatial extent of subsurface contamination and identifying the transport-flow directions and fates of the contaminants are essential to developing safe, effective, and costsensitive remediation strategies. Yet tracing preferential permeability paths in sufficient detail to allow quantitative analysis is among the most challenging problems facing hydrologists. Imaging technologies such as SSR and GPR sometimes are capable of identifying geologic conditions that might indicate preferential flow paths. However, no single sensing technique is able to detect and image all of the various geological and soil conditions to be found across the country. Some of the factors limiting the accuracy of hydrologic predictions are lateral heterogeneity, unexpected stratigraphic layering, fracturing, and flow anisotropy. Commonly, our knowledge of these controlling hydrologic factors is derived from conceptual knowledge of regional geology coupled with information derived from drilling. However, invasive processes such as drilling are time consuming, costly, and can exacerbate existing problems. Furthermore, the information obtained from them is point-specific and may not provide the detail needed about the region between drilled holes. A combined seismic/GPR imaging approach has the potential to offer a low-impact, lowercost alternative at some sites.

During the first three years of funding we imaged a cone of depression around a pumping well using seismic data. Although we were successful in imaging the same geologic interfaces with both P-wave seismic reflection and GPR methods (Baker et al. 1999b, 2001), we were not able explicitly to delineate the cone of depression (Johnson 2003). We believe this was due partly to the depositional complexity of the alluvial aquifers at the test sites and partly to the gradational nature of the capillary fringe found immediately above the water table.

Field surveys employing both SSR and GPR were conducted in October 1997; March, June, September, and November 1998; and March 1999. Our test site was the alluvial valley of the Arkansas River near Great Bend, Kansas. We successfully used seismic $P$-wave reflection to survey depths ranging from 0.6 to $3 \mathrm{~m}$. We were able to complement and, to a substantial degree, duplicate those results with GPR surveys along the same test lines. Finite-difference waveequation modeling supported the results obtained from both types of surveys. Because of the unexpected detection of three $P$-wave reflections at depths of less than $3 \mathrm{~m}$, we concentrated our efforts in a zone somewhat shallower than originally envisioned. Baker et al. (1999a) established that seismic reflection methods could be used at depths as small as about $1 \mathrm{~m}$. Steeples et al. (1999a) showed that it is conceptually possible to design an apparatus and a procedure capable of collecting data at these very shallow depths by using automatically planted geophones, allowing faster and cheaper application SSR methods.

In 2000-2004 we built and field-tested first- and second-generation versions of an automatic planting device - the Autojuggie. Initially, experimental common-midpoint (CMP) reflection data were collected using the Autojuggie at three test sites with varying near-surface geology near Lawrence, Kansas (Spikes 2002). Two parallel lines, referred to here as the test line and the comparison or control line, were positioned about $0.5 \mathrm{~m}$ apart. Each line consisted of 72 geophones with intervals of $12 \mathrm{~cm}$. In using the Autojuggie on the test line, all of the geophones were planted mechanically by two people within approximately one minute.

The planting rate is limited currently by the hydraulic-pump capacity of the seismic recording truck. In these experiments, geophones were bolted rigidly to the channel iron that was connected via 
steel pins to hydraulic cylinders attached to the frame of the Autojuggie. Comparison-line data were collected using traditional methods in which 72 geophones were planted by hand in a line parallel to the test line, a process that took four people approximately 15 minutes. The comparison line served as an experimental control whose purpose was to disclose any effects on the recorded data produced by bolting the geophones to a long, rigid medium.

On each of the geophone lines, Mark Products L-40A, 100-Hz geophones were positioned at intervals of $12 \mathrm{~cm}$ and equipped with spikes $12.5 \mathrm{~cm}$ long. Data on both lines were recorded with 72-channel Geometrics Strataview seismographs. Both seismographs have 24-bit analog-to-digital (A/D) conversion, and both seismographs recorded data from each shot to remove source variability from the comparison aspects of the experiments.

Each of the 72 geophones was screwed into a 9.5-mm (3/8-in) NF-threaded nut welded to the head of an NF-threaded bolt $3 \mathrm{~cm}$ long and $9.5 \mathrm{~mm}$ in diameter. The bolts were inserted into the channel iron through $9.5 \mathrm{~mm}$ holes and fastened with $9.5 \mathrm{~mm}$ NF-threaded nuts. Geophone spikes $12.5 \mathrm{~cm}$ long were screwed onto the ends of the bolts. Pairs of hydraulic cylinders attached to each 2.8-mlong section were used to force the channel iron downward.

In addition, Blair (2003) conducted experiments at one of our test sites to determine the effect, if any, of geophone spike length on time- and frequency-domain seismic data. Geophones were rigidly attached to channel iron and then planted automatically (Blair et al. 2003). The spikes tested were $27 \mathrm{~cm}, 21 \mathrm{~cm}, 12.6 \mathrm{~cm}$, and $7.6 \mathrm{~cm}$ long. Based on an analysis of the resulting test and control data, the longer geophone spike lengths yielded an advantage of only about $3 \mathrm{~dB}$ at frequencies $<140 \mathrm{~Hz}$.

The original Autojuggie was fabricated on a modified trailer previously used to transport agricultural implements, with the geophones mounted under the trailer. We performed a series of experiments on the test- and comparison-geophone lines simultaneously to compare the recorded wave fields for the two lines. The two data sets are virtually equivalent, although the data from the Autojuggieplanted line appear to be less ringy. A field experiment at another test site indicated that data collected by the Autojuggie were superior to data collected using conventional geophone plants on a day when sustained winds of about $30 \mathrm{mph}$ were noted. The attenuation of wind-generated noise was an unexpected benefit of the Autojuggie.

Over the first three years of funding, we concentrated our experiments on channel iron as the connecting medium for the geophones. However, one of the goals of the more recent funding period was to determine whether channel iron is the best material for the job, and results showed that square tubing is significantly better. Results (Blair 2003; Blair et al. 2003) indicate that our data collection system can be improved by modifying the design to include steel media with other crosssectional shapes. Blair conducted experiments using rigid media with varying cross-sectional shapes at two sites and replicated the experiments at each site to verify the experimental repeatability of the results. The seismic sources tested for these experiments included a .223caliber rifle, a 30-06 rifle (further described in Miller et al. 1986) and a sledgehammer. Prior to firing, the muzzle of each rifle was placed in a pre-punched hole about $25 \mathrm{~cm}$ deep.

The reflection data from the square tubing are clearly superior to the data from the conventional geophone plants. Specifically, the reflection event at $80 \mathrm{~ms}$ is more coherent in the square-tubing 
data than it is in the conventional-plant data, especially at shot-to-geophone offsets from 3 to $30 \mathrm{~m}$. In addition, the airwave effects are more severe in the conventional-plant data than they are in the square-tubing data, which is another significant and unexpected benefit of Autojuggie use. Usable surface-wave information also has been retained in the square-tubing data. In addition, we have also used the Autojuggie to collect surface-wave imaging data (Tian et al. 2003) by applying the multichannel analysis of surface waves (MASW) technique (Park et al. 1999; Xia et al. 1998).

Following on Blair's research, we conducted experiments to determine the effect of variations of azimuthal orientation of steel tubing in relation to the source location. These experiments indicate a $\sim 60^{\circ}$ zone of airwave degradation off of both ends of the bar in which the coherency and amplitude of the recorded airwave are sharply reduced. For shots in the crossline direction, the airwave is shown to have more reverberation cycles; this adversely affects the signal-to-noise ratio.

The Autojuggie is useful for Rayleigh-wave analyses of data collected with vertical geophones, but the analysis of horizontal-component $S$-waves and Love waves is proving to be more challenging. In addition to the $P$-wave and other vertical-component work described above, we have been examining the total-vector wavefield to better understand how we might improve both vertical and $3 \mathrm{C}$ automated seismic data recording. Our $3 \mathrm{C}$ geophones employ the Galperin configuration, in which the three geophones are positioned orthogonally with respect to each other but are mounted at an angle of 35.3 degrees with respect to the ground (Galperin 1974; Goff and O'Brien 1981). Three sets of $3 \mathrm{C}$ geophones were used for this experiment: one with conventional plants (control line); one set bolted to the channel iron and connected to a spike (test line); and one set bolted to the edge of the channel iron but without a spike attached (bar-motion line). The goal of the experiment was to measure the seismic-vector response of the channel-iron bar in relation to the motion of the ground and to see how the resulting data compared to the test- and control-line data.

Records of the full-vector seismic wavefield acquired with this field configuration reveal multicomponent crosstalk. The crosstalk results from the rigid-body bulk excitation of the channel iron by seismic ground motion. The first channel of radial-component motion on the test-line array and the bar-motion array attached to the channel iron appears to have been replicated on the neighboring seven channels. That is, the radial component of seismic ground motion recorded by the receiver nearest the source on each of the receiver arrays appears to interfere with the neighboring channels in the array. The transverse-component seismograms acquired with the testline array and the bar-motion array are distorted in both amplitude and phase. However, the nature of the crosstalk among the transverse-component seismograms is not as apparent visually as it is in the corresponding radial-component seismograms. Vertical-component seismograms acquired with the test-line array and the bar-motion array are equivalent to those acquired with the control line when geophones are attached to channel iron (Spikes et al. 2001; Ralston et al. 2001).

Snapshots of the radial-, transverse-, and vertical-components of motion recorded by each of the three receiver spreads during Rayleigh-wave arrival illustrate the nature of the crosstalk. The snapshots of radial-component motion show clearly that the test-line receivers respond rigidly to the motion of the bar (as seen by the bar-motion array) rather than to the seismically induced motion of the ground. The snapshots of transverse-component motion show that the test-line receivers respond to flexural modes in the channel-iron induced by seismic ground motion. The snapshots of vertical-component motion show first that the test-line receivers respond in-phase to the vertical 
component of seismic ground motion and, second, that the channel iron itself appears to be flexible enough in the vertical direction to allow the vertical component of seismic ground motion to be acquired with near-perfect fidelity on the bar-motion receivers. These results illustrate why the Autojuggie concept works well for $P$-wave surveys but poses a challenge yet to be conquered in $3 \mathrm{C}$ surveys.

Crosstalk among the radial- and transverse-component seismograms may be removed by modeling the array of rigidly interconnected receivers as a linear system and deriving a time- or frequencydomain estimate of the system's response. An estimate of the system response of the channel-iron in the form of a time- or frequency-domain filter would provide a means to remove the crosstalk from seismic field files through the process of inverse filtering. However, variations in the effective ground coupling of a receiver array have a direct impact on the response of the array. The implications of this finding are (1) that a sole shaping filter cannot be computed from a small subset of calibration data and subsequently used throughout an entire seismic survey, and (2) that a unique shaping filter is required for each placement of the receiver array during the course of the survey. Consequently, using the Autojuggie for $3 \mathrm{C}$ data collection will require either inventive inverse filtering or the use of a different medium to interconnect the geophones. We do not think that this is a permanent obstacle to Autojuggie-based $3 \mathrm{C}$ data collection; rather, it represents a conundrum that we are trying to solve.

Along with its overall portability, another benefit of the Autojuggie is that the electronic connector cables remain attached to the geophones and to the seismograph when the planting device is moved from one location to another. The use of square tubing or round pipe would offer the additional advantage of protecting the geophones and cables from weather, vandalism, and tangling during the planting process. Also, both geophones and cabling would be less susceptible to damage by physical impacts or abrasion. These benefits, combined with the automatic geophoneplanting capability, would make a significant difference in the number of person-hours required to execute a seismic survey. Furthermore, with the Autojuggie, the operator runs a hydraulic lever while seated in a motorized apparatus as opposed to having to stoop repeatedly, as is required when geophones are planted and retrieved manually.

\section{References cited (other than research supported by this DOE grant)}

Galperin, E. I., 1974, Vertical seismic profiling: Soc. Expl. Geophys. Special Publication, Tulsa, OK, USA.

Goff, D. D., and O’Brien, J. T., Phillips Petroleum Company, 1981, Three-component detector and housing for same: A detector utilizing three seismometers is provided which is operable to detect three components of particle motion waves: U. S. Patent No. 4,300,220, issued 11/10/1981.

Miller, R. D., S. E. Pullan, J. S. Waldner, and F. P. Haeni, 1986, Field comparison of shallow seismic sources: Geophysics, 51, 2067-2092.

Park, C. B., R. D. Miller, and J. Xia, 1999, Multichannel analysis of surface waves (MASW): Geophysics, 64, 800-808.

Xia, J., R. D. Miller, C. B. Park, and J. Hunter, 1998, Comparison of shear wave velocities from MASW technique and borehole measurements in unconsolidated sediments of the Fraser River Delta: Kansas Geological Survey Open-file Report 98-58. 


\section{RESEARCH PRODUCTS SUPPORTED BY DOE-FUNDED RESEARCH}

\section{Dissertations and Theses 1998-2005}

Sloan, Steve, to be submitted spring 2005 , Using shallow seismic reflection methods to image the cone of depression, Clay Center, KS: M.S. thesis, The University of Kansas.

Vincent, Paul D., to be submitted spring 2005, Removing the bar effect from bar-mounted geophone acquired data: M.S. thesis, The University of Kansas.

Clark, Jennifer M., 2004, Seismic response of attached geophones to tubing: M.S. thesis, The University of Kansas.

Blair, Jason D., 2003, Analysis of the seismic response of rigidly interconnected geophones attached to variously shaped steel media: M.S. thesis, The University of Kansas.

Johnson, Elizabeth, 2003, Imaging the cone of depression around a pumping well using shallow seismic reflection: M.S. thesis, The University of Kansas.

Ralston, Matthew R., 2003, New approaches to seismic data acquisition: Ph.D. dissertation, The University of Kansas.

Spikes, Kyle T., 2002, Recording near-surface common-midpoint seismic data with automatically planted geophones: M.S. thesis, The University of Kansas.

Pavlovic, Mario, 2000, Ground-penetrating radar in shallow aquifer detection and monitoring: M.S. thesis, The University of Kansas.

Baker, Gregory S., 1999, Seismic imaging shallower than three meters: Ph.D. dissertation, The University of Kansas.

Schmeissner, Curtis M., 1998, Seismic detectability of vertical transverse isotropy in the nearsurface: Ph.D. dissertation, The University of Kansas.

\section{Refereed Papers 1997-2004}

In review or revision

Baker, G. S., D. W. Steeples, and C. Schmeissner, 2003, Shallow underground reflection feasibility (SURF) diagrams: Environmental and Engineering Geoscience, in revision.

Ralston, M. D. and D. W. Steeples, 2003, Automated orientation of three-component shallow seismic land data to source-centered cylindrical coordinates: Geophysics, Soc. Of Expl. Geophys., in review.

Ralston, M. D., D. W. Steeples, and R. Black, 2003, Field measurements of the P- and S-wave velocity of soils: Geophysics, Soc. Of Expl. Geophys., in review.

Spikes, K. T., P. D. Vincent, and D. W. Steeples, 2003, Near-surface common-midpoint seismic data recorded with automatically planted geophones: accepted by Geophysical Prospecting with revision.

\section{Papers and Maps Published}

Vincent, P. D., G. P. Tsoflias, S. D. Sloan, and D. W. Steeples, 2004a, Processing ultra-shallow reflection data in areas with laterally varying velocities: Eos Trans. AGU, 85(46), Fall Meet. (13-17 Dec. 2004, San Francisco) Suppl. Abstract H14C-05.

Clark, J.M., J.D. Blair, D.W. Steeples, P.D. Vincent, and S.D. Sloan, 2004, Seismic response of attached geophones to tubing: expanded abstract, Soc. Of Expl. Geophys. 74th Ann. Internat. Mtg. (Oct. 2004), Soc. Of Expl. Geophys., NSG 1.2.

Vincent, P.D., D.W. Steeples, J.D. Blair, and G.P. Tsoflias, 2004b, Effect of orientation of hollow-barmounted geophones on airwave coherency: expanded abstract, 74th Ann. Internat. Mtg. (Oct. 2004), Soc. Of Expl. Geophys., NSG 1.3.

Blair, J.D., J. Clark, D.W. Steeples, P.D. Vincent, and G.P. Tsoflias, 2004, Reducing the cost of shallow seismic data acquisition: A comparative analysis of the seismic response of rigidly interconnected geophones attached to steel media of various shapes: 227th meeting of the American Chemical Society (March 28-April 1, 2004, Anaheim, CA): ENVR 74. 
Baker, G .S., D. W. Steeples, and C. Schmeissner, 2003, The effect of seasonal soil-moisture conditions on near-surface seismic reflection data quality: First Break, 20, no. 1, 35-41.

Blair, J.D., D.W. Steeples, P. D. Vincent, N. Butel, and J. Powers, 2003a, Analysis of the seismic response of rigidly interconnected geophones attached to steel media of various shapes: 73rd Ann. Internat. Mtg.: Soc. of Expl. Geophys., 1263-1265.

Blair, J. D., D. W. Steeples, P. D. Vincent, N. Butel, and J. Powers, 2003b, Field testing hydraulically planted receivers fitted with custom-made spikes: 73rd Ann. Internat. Mtg.: Soc. of Expl. Geophys., 1266-1269.

Healey, J.M., G.P. Tsoflias, D.W. Steeples, P.D. Vincent, S.D. Sloan, C.D. McElwee, J. D. Blair, 2003, Geophysical techniques applied to a stream-aquifer system: Eos Trans. AGU, 84(46), Fall Meet. Suppl., Abstract H31B-0466.

Tian, G., D.W. Steeples, J. Xia, and K. T. Spikes, 2003a, A useful resorting in surface wave method with the Autojuggie: Geophysics, Soc. Of Expl. Geophys., 68, no. 6, 1906-1916.

Tian, G. D. W. Steeples, J. Xia, R. D. Miller, K. T. Spikes, and M. D. Ralston, 2003b, Multichannel analysis of surface-wave method with the Autojuggie: Soil Dynamics and Earthquake Engineering, 23, no. 3, 61-65.

\section{2}

Ralston, M. D. and D. W. Steeples, 2002, Automated orientation of three-component shallow seismic land data to source-centered cylindrical coordinates: 72nd Ann. Internat. Mtg: Soc. of Expl. Geophys., 1420-1423.

Ralston, M. D., D. W. Steeples, K. T. Spikes, J. D. Blair, and G. Tian, 2002, Analysis of an automated three-component shallow seismic acquisition system: 72nd Ann. Internat. Mtg: Soc. of Expl. Geophys., 1551-1554.

\section{1}

Baker, G. S., D. W. Steeples, C. Schmeissner, M. Pavlovic, and R. Plumb, 2001, Near-surface imaging using coincident seismic and GPR data: Geophysical Research Letters, 28, no. 4, $627-630$.

Ralston, M. D., D. W. Steeples, K. T. Spikes, and J. D. Blair, 2001, Near-surface three-component seismic data acquisition using rigidly interconnected geophones: 71st Ann. Internat. Mtg: Soc. of Expl. Geophys., 1411-1414.

Schmeissner, C. M., K. T. Spikes, and D. W. Steeples, 2001, Recording seismic reflections using rigidly interconnected geophones: Geophysics, 66, no. 6, 1838-1842.

Spikes, K. T., D. W. Steeples, C. Schmeissner, R. Prado, and M. Pavlovic, 2001a, Varying the effective mass of geophones: Geophysics, 66, no. 6, 1850-1855.

Spikes, K. T., M. D. Ralston, and D. W. Steeples, 2001b, Obtaining CMP data with automatically planted geophones: 71st Ann. Internat. Mtg: Soc. of Expl. Geophys., 1369-1372.

Steeples, D. W., 2001, Engineering and environmental Geophysics at the millennium: Geophysics, 66 , no. 1, 31-35.

2000

Baker, G., C. McIntyre, L. Walczak, and D. W. Steeples, 2000a, Improving ultrashallow seismic reflection data by reducing source energy: 70th Ann. Internat. Mtg: Soc. of Expl. Geophys., Calgary, Canada, vol. II, 1267-1270.

Baker, G. S., D. W. Steeples, C. Schmeissner, and K. T. Spikes, 2000b, Ultrashallow seismic reflection monitoring of seasonal fluctuations in the water table: Environmental and Engineering Geoscience, 6, no. 3, 271-277.

Baker, G. S., D. W. Steeples, C. Schmeissner, and K. T. Spikes, 2000c, Source-dependent frequency content of ultrashallow seismic reflection data: Bull. Seis. Soc. Amer., 90, no. 2, 494-499. 
Baker, G. S., D. W. Steeples, C. Schmeissner, and K. T. Spikes, 2000d, Collecting seismic-reflection data from depths shallower than three meters: in Proc. of the Symposium on the Application of Geophysics to Engineering and Environmental Problems (SAGEEP), Washington, D.C., 1207-1214.

Schmeissner, C., D. W. Steeples, Mario Pavlovic, Renato Prado, and Kyle Spikes, 2000, Recording seismic reflections using rigidly interconnected geophones: 70th Ann. Internat. Mtg., Soc. of Expl. Geophys., Calgary, Canada, Vol. II, 1279-1282.

Spikes, K. T., D. W. Steeples, C. Schmeissner, and R. Prado, 2000, Varying the effective mass of geophones: 70th Ann. Internat. Mtg: Soc. of Expl. Geophys., Calgary, Canada, vol. II, 1385-1388.

\section{9}

Baker, G. S., C. Schmeissner, and D. W. Steeples, 1999a, Seismic reflections from depths of less than two meters: Geophysical Research Letters: 26, no. 2, 279-282.

Baker, G. S., D. W. Steeples, and C. Schmeissner, 1999b, On coincident seismic and radar imaging: 69th Ann. Internat. Mtg., Soc. of Expl. Geophys., 484-487.

Baker, G. S., D. W. Steeples, and C. Schmeissner, 1999c, In-situ, high-frequency P-Wave velocity measurements within $1 \mathrm{~m}$ of the Earth's surface: Geophysics, 64, no. 2, 323-325.

Steeples, D. W., G. S. Baker, and C. Schmeissner, 1999a, Toward the autojuggie: Planting 72 geophones in 2 seconds: Geophysical Research Letters, 26, no. 8, 1085-1088.

Steeples, D. W., G. S. Baker, C. Schmeissner, and B. K. Macy, 1999b, Geophones on a board: Geophysics, 64, no. 3, 809-814.

\section{8}

Baker, G. S., R. Plumb, D. W. Steeples, M. Pavlovic, and C. Schmeissner, 1998a, Coincident GPR and ultrashallow seismic imaging in the Arkansas River Valley, Great Bend, KS: 68th Ann. Internat. Mtg: Soc. of Expl. Geophys., 859-861.

Baker, G. S., D. W. Steeples, and M. Drake, 1998b, Muting the noise cone in near-surface reflection data: An example from southeastern Kansas: Geophysics, 63, no. 4, 1332-1338.

Baker, G. S., D. W. Steeples, C. Schmeissner, and B. K. Macy, 1998c, In-situ, high-resolution Pwave velocity measurements within $1 \mathrm{~m}$ of the Earth's surface: 68th Ann. Internat. Mtg: Soc. of Expl. Geophys., 856-858.

Jefferson, R. D., D. W. Steeples, R. A. Black, and T. Carr, 1998, Effects of soil-moisture content on shallow seismic data: Geophysics, 63, no. 4, 1357-1362.

Miller, R. D., J. Xia, and D.W. Steeples, 1998, Shallow reflection does not always work: 68th Ann. Internat. Mtg., Soc. of Expl. Geophys., 852-855.

Steeples, D. W., 1998, Shallow seismic reflection section: Introduction, Geophysics, 63, no. 4, 1210-1212.

Steeples, D. W. and Gregory S. Baker, 1998, Finding seismic static corrections: AAPG Explorer, 19, no. 6, 20-21; 29.

Steeples, D. W. and R. D. Miller, 1998, Avoiding pitfalls in shallow seismic reflection surveys: Geophysics, 63, no. 4, 1213-1224.

Steeples, D. W., G. S. Baker, C. Schmeissner, and B. K. Macy, 1998, Geophones on a board: Geophysics, Soc. of Expl. Geophys., 64, 809-814.

1997

Baker, G. S., D. W. Steeples, and M. Feroci, 1997, The time dependence of shallow reflection data: The Leading Edge, 16, no. 11, 1663-1666.

Steeples, D. W., C. Schmeissner, and B. Macy, 1997a, Recording wind microstructure with a seismograph: Geophys. Res. Lett., 24 , no. 19, 2375-2378.

Steeples, Don W., A. G. Green, T. McEvilly, R. D. Miller, W. E. Doll, and J. W. Rector, 1997b, A workshop examination of shallow seismic reflection surveying: The Leading Edge, 16, no. 11, 1641-1647. 